\title{
Practical considerations for developing a lung transplantation anesthesiology program
}

\author{
Ashley Virginia Fritz ${ }^{1} \cdot$ Archer Kilbourne Martin $^{2}$ (D) $\cdot$ Harish Ramakrishna ${ }^{1}$ \\ Received: 18 March 2021 / Revised: 23 April 2021 / Accepted: 14 May 2021 / Published online: 3 September 2021 \\ (C) Indian Association of Cardiovascular-Thoracic Surgeons 2021
}

\begin{abstract}
The advancement in lung transplantation outcomes has been secondary to ongoing improvements within multiple medical specialties. The recent emergence of literature describing the impact of anesthetic management on perioperative outcomes has led to the beginnings of formalized training fellowships within lung transplantation anesthesiology. Practical considerations for the development of a lung transplantation anesthesiology program, both clinical and educational, are herein described.
\end{abstract}

Keywords Lung transplantation $\cdot$ Thoracic surgery $\cdot$ Cardiothoracic anesthesiology $\cdot$ Education $\cdot$ Fellowship

\section{Introduction}

The fields of lung transplantation and cardiothoracic anesthesiology have evolved rapidly since Dr. James Hardy performed the first human lung transplant in 1963 [1,2]. In the 58 years since, advancements in both basic and clinical science have allowed for the completion of over 70,000 lung transplants [3]. In addition, the inception of the International Society for Heart and Lung Transplantation (ISHLT) and International Thoracic Organ Transplant (TTX) Registry has created a network for advanced analysis and data exchange, setting forth the framework for increased multidisciplinary teamwork similar to that modeled by the Toronto Lung Transplant Group [4]. Improvements in the science of circulatory support, surgical technique, and intraoperative anesthetic management have contributed to significantly improve the survival and perioperative outcomes in the lung transplant patient population $[5,6]$. Perioperative care provided by lung transplant anesthesiolo-

Archer Kilbourne Martin

Martin.Archer@mayo.edu

1 Division of Cardiovascular and Thoracic Anesthesiology, Department of Anesthesiology and Perioperative Medicine, Mayo Clinic, Rochester, MN, USA

2 Division of Cardiovascular and Thoracic Anesthesiology, Department of Anesthesiology and Perioperative Medicine, Mayo Clinic, 4500 San Pablo Road, Jacksonville, FL 32224, USA gists can directly affect patient outcomes through optimized perioperative management aimed to prevent or minimize primary graft dysfunction [4]. In addition, a focus on minimizing technical complications and judicious blood management can improve patient outcomes. For instance, technical complications, such as airway and vascular injury, have been reported as the cause for over $11 \%$ of $0-30$-day perioperative mortality [4]. We propose that the development of a lung transplant anesthesiology program will not only provide the benefits of education in basic science, multidisciplinary research, and clinical excellence, but also encourage a positive impact on patient outcomes. In a recent white paper by the Society for the Advancement of Transplant Anesthesia (SATA), milestones were established to guide lung transplant education in adult cardiothoracic anesthesiology fellowship programs. In addition, SATA experts argued that anesthesia for lung transplantation requires targeted learning goals, milestones, and continued practice to gain proficiency [7]. The authors of this manuscript concur, and further recommend the following specific clinical and educational considerations for the development of a comprehensive lung transplant anesthesiology program. While currently there are no formal lung transplant anesthesia fellowships, the authors propose that the following considerations (Table 1) should serve as a platform for minimum clinical and educational requirements in lung transplant anesthesia, whether through incorporation within cardiac anesthesiology fellowship curriculum or as a standalone educational program for cardiothoracic anesthesiologists. 
Table 1 Key clinical and educational considerations of a lung transplant anesthesiology program

Fundamental anesthesia skills

- Basic surgical steps of lung transplantation

- Advanced airway isolation techniques, to include double lumen endotracheal tube management

- Advanced perioperative echocardiography

- Regional analgesic techniques

Preoperative management

- Understanding of National organ allocation policy

- Knowledge of ex-vivo lung perfusion techniques

- Institutional multidisciplinary preoperative optimization protocols

- Engagement within the transplant selection committee process

- Anesthetic planning tailored to etiology of recipient end-stage lung disease

Intraoperative Management

- Lung protective ventilatory strategy tailored to etiology of recipient end-stage lung disease

- Institutional multidisciplinary protocol regarding initiation of mechanical circulatory support

- Blood management strategy aimed at reducing transfusion of products

- Intraoperative echocardiography to assess pulmonary vasculature anastomoses

Postoperative management

- Institutional multidisciplinary early recovery protocols

- Postoperative analgesia service with a focus on regional anesthetic techniques

- Postoperative echocardiography service to provide rapid assessment and diagnosis of cardiopulmonary instability

\section{Preoperative management of lung transplantation}

\section{Exploring the foundations in the management of lung transplantation}

There are many basic principles that are essential to lung transplant anesthesia education and clinical practice. These principles are common in any fundamental anesthesia program and not specific to the practice of lung transplant anesthesia. These basics which are outlined in the SATA milestones include developing the ability to effectively communicate with the patient, family, and multidisciplinary team members, identifying patient safety issues, and demonstrating effective medical documentation [7]. In addition, performing an appropriate history and physical examination, assessing the patient's clinical status, airway management for lung isolation, and safely performing vascular access are all vital competencies that must be mastered before entering transplant anesthesiology training [7]. Lung isolation utilizing doublelumen endotracheal tubes and endobronchial blockers is a key element in cardiothoracic anesthesia that is a translatable skill to lung transplant anesthesia. It is imperative for the anesthesiologist to understand the basic concepts of lung isolation, including necessary safeguards and pitfalls. Core foundations vital to a successful lung transplantation team member that should be considered part of the curriculum in any anesthesiology transplant program include understanding organ allocation, donor classifications and characteristics, basics of exvivo lung perfusion, and basic surgical steps of lung transplantation. These skills bridge across all medical specialties and are essential in becoming a leader in the lung transplantation team.

\section{Exploring the role of anesthesiologists' preoperative management in lung transplantation}

Transplant specific anesthesia education begins before walking into the operating theater and relies on a strong foundational knowledge of basic anesthesia and physiologic concepts, including the underlying physiology of etiologyspecific disease processes. Recent literature supports tailoring anesthetic management to the underlying etiology in order to improve perioperative outcomes $[4,5,8]$. As such, it is imperative that the anesthesiologist commands the full ability to optimize the anesthetic management and patient physiology in patients with pulmonary hypertension, obstructive pulmonary disease, suppurative pulmonary disease, and restrictive pulmonary disease. Enhanced recovery after surgery (ERAS) pathways should start in the preoperative period and the anesthesiologist plays a key role in the multidisciplinary clinical care pathway of treatment. While no formal protocols have been established for lung transplant patients, focusing on fundamentals of preoperative care optimization including nutrition, baseline cardiopulmonary status, multimodal analgesia, fluid management, and early mobilization is essential [9].

\section{Intraoperative management of lung transplantation}

Although no data exist in the literature today supporting a positive impact on lung transplant outcomes from preoperative management, there are a myriad of data supporting the impact of intraoperative management [4]. When appropriately managed, anesthetic variables can influence outcomes such as primary graft dysfunction (PGD) and complications [4] (Table 2). This further emphasizes the need for standardized clinical and educational approaches in the areas of anesthetic and airway management, ventilation and oxygenation strategies, mechanical circulatory support, intraoperative echocardiography, and intraoperative transfusion management [7].

\section{Intraoperative anesthetic and ventilator management strategies}

Understanding the role that anesthesiologists play on the intraoperative management is key when developing a lung transplant anesthesiology program. One of the most crucial 
Table 2 Intraoperative anesthetic variables influencing PGD and technical complications (used with permission from Martin, A.K. et al., 2020) [4]

\begin{tabular}{|c|c|}
\hline Factor & Impact \\
\hline $\mathrm{F}_{\mathrm{I}} \mathrm{O}_{2}>0.4$ used during reperfusion & Increased primary graft dysfunction \\
\hline $\begin{array}{l}\text { Increased administration of blood } \\
\text { products }\end{array}$ & $\begin{array}{l}\text { Increased risk of mortality and } \\
\text { development of PGD }\end{array}$ \\
\hline Increased intraoperative fluid administration & Increased risk of PGD grade 3 \\
\hline Intraoperative echocardiography & $\begin{array}{l}\text { Decreased technical complications in } \\
\text { ECMO placement, indirect impact } \\
\text { on facilitating PGD-reducing } \\
\text { management strategies }\end{array}$ \\
\hline Protective ventilation strategy & $\begin{array}{l}\text { Animal model shows attenuation of } \\
\text { ischemic-reperfusion injury and } \\
\text { improved lung function post-transplant }\end{array}$ \\
\hline Use of propofol as TIVA & $\begin{array}{l}\text { Decreased incidence of acute kidney } \\
\text { injury as compared to sevoflurane }\end{array}$ \\
\hline Use of sevoflurane preconditioning & $\begin{array}{l}\text { Animal model shows increased } \mathrm{PaO}_{2} / \mathrm{F}_{\mathrm{I}} \mathrm{O}_{2} \\
\text { ratio, increased anti-inflammatory } \\
\text { cytokines, decreased proinflammatory } \\
\text { cytokines }\end{array}$ \\
\hline
\end{tabular}

$E C M O$, extracorporeal membrane oxygenation; $F_{I} \mathrm{O}_{2}$, fraction of inspired oxygen; $P G D$, primary graft dysfunction; TIVA, total intravenous anesthesia steps in lung transplantation anesthesia is taken in airway management and induction of anesthesia, especially for high-risk patients. Understanding the underlying etiology for which the patient is being transplanted allows for a tailored induction and maintenance of anesthesia [8]. Lung transplant patients have poor pulmonary reserve and often those with pulmonary hypertension have right ventricular dysfunction. In combination, these physiologic characteristics can lead to hemodynamic crisis on induction of anesthesia. A critical part of lung transplant management is learning these key characteristics and skillfully manipulating anesthetic techniques for optimized outcomes (Table 3 ). In patients with pulmonary hypertension and right ventricular dysfunction, it is imperative to account for changes in right ventricular preload or afterload caused by fluid shifts, medications, hypoxia, or hypercapnia [10]. In addition, clear understanding and mastery of complex fiber-optic bronchoscopy, lung isolation techniques, and identification of airway anatomy, including bronchial segments and anastomoses, are paramount in lung transplant anesthesia [7]. For instance, in patients with suppurative disease, it is prudent to consider placement of a single-lumen tube immediately upon induction with subsequent therapeutic bronchoscopy or decontamination protocol [11].

Another key element of lung transplant anesthesiology is ventilator management strategy. Foundational knowledge of oxygenation and ventilation physiology is built upon in combination with the key understanding of characteristics from the underlying etiology of the patient's presenting disease. For instance, obstructive lung disease ventilation strategies aim to avoid hyperinflation, reduce peak airway pressures, lower tidal volumes, longer expiratory times, and increase respiratory rates and possible permissive hypercapnia, while balancing any potential complications as a result [8]. Similar strategies should be applied for oxygenation and ventilation for each underlying etiology. Another key emphasis for education is ventilator management during and after allograft reperfusion. Acute lung injury, secondary to ventilator-induced lung injury on the allograft, can lead to primary graft dysfunction [12]. As such, clinical management should be focused on appropriate ventilation strategies that minimize lung injury. While there are no current consensus statements or guidelines for allograft ventilation, experts agree on utilizing overall lung protective ventilation strategies, with augmentation of inhaled pulmonary vasodilators, and mechanical circulatory support as needed for respiratory failure [7].

\section{The anesthesiologists' role in the management of mechanical circulatory support (MCS)}

Institutional predilection and protocols, patient physiology, underlying etiology, prior surgeries, and surgeon preference all contribute to the determination if a recipient will undergo lung transplantation on cardiopulmonary bypass (CPB), extracorporeal membrane oxygenation (ECMO), or in some cases with no mechanical circulatory support (MCS). The anesthesiologist must learn the key principles and main roles of MCS for lung transplantation [7]. A strong grasp of rudimentary knowledge such as cannulation strategies, anticoagulation management, weaning strategies, and manipulation of fresh gas flow or "sweep" and circuit flow to maintain oxygenation must be obtained in order to build upon in a transplant anesthesiology program. A successful lung transplant anesthesiology training program will encompass both these basic concepts with more advanced topics. Educational areas of emphasis should include 
Table 3 Key points for perioperative management of presenting disease (used with permission from Martin, A.K. et al.) [8]

\begin{tabular}{|c|c|c|c|c|}
\hline $\begin{array}{l}\text { Presenting } \\
\text { disease }\end{array}$ & Suppurative & Obstructive & Restrictive & Pulmonary hypertension \\
\hline \multicolumn{5}{|l|}{ Phase of care } \\
\hline Preoperative & $\begin{array}{l}\text { Assess for presence of } \\
\text { chronic infection } \\
\text { Perform vascular } \\
\text { access ultrasound to } \\
\text { plan venous and } \\
\text { arterial access }\end{array}$ & $\begin{array}{l}\text { Review pulmonary function tests and } \\
\text { imaging to assess degree of obstructive } \\
\text { disease } \\
\text { Ensure administration of bronchodilation } \\
\text { medications } \\
\text { Assess preoperative carbon dioxide levels } \\
\text { on arterial blood gas to stratify risk on } \\
\text { induction }\end{array}$ & $\begin{array}{l}\text { Assess for common } \\
\text { preexisting } \\
\text { comorbidities } \\
\text { including GERD and } \\
\text { secondary pulmonary } \\
\text { hypertension } \\
\text { Take thorough history } \\
\text { regarding use of novel } \\
\text { antifibrotic } \\
\text { medications }\end{array}$ & $\begin{array}{l}\text { Take thorough history regarding } \\
\text { functional status and other factors } \\
\text { associated with poor outcome } \\
\text { Review preoperative } \\
\text { echocardiography for } \\
\text { biventricular function and the } \\
\text { presence of RVH }\end{array}$ \\
\hline Intraoperative & $\begin{array}{l}\text { Consider } \\
\text { decontamination } \\
\text { protocol if chronic } \\
\text { infection exists } \\
\text { Place single-lumen } \\
\text { tube immediately } \\
\text { and perform thera- } \\
\text { peutic bronchosco- } \\
\text { py } \\
\text { Consider utilization of } \\
\text { VA ECMO as } \\
\text { preferred } \\
\text { intraoperative } \\
\text { cardiac support }\end{array}$ & $\begin{array}{l}\text { Consider lung hyperinflation as a cause of } \\
\text { hypertension } \\
\text { Consider ventilation strategies that } \\
\text { incorporate prolonged expiratory time } \\
\text { Consider utilization of VA ECMO as } \\
\text { preferred intraoperative cardiac support }\end{array}$ & $\begin{array}{l}\text { Consider elevated } \\
\text { inspiratory pressures in } \\
\text { the setting of decreased } \\
\text { compliance as a cause } \\
\text { of hypotension } \\
\text { Consider utilization of } \\
\text { VA ECMO as } \\
\text { preferred intraoperative } \\
\text { cardiac support }\end{array}$ & $\begin{array}{l}\text { Consider awake cannulation for } \\
\text { immediate ECMO support } \\
\text { preinduction } \\
\text { High-risk waypoints during } \\
\text { induction include positive } \\
\text { pressure ventilation, decreasing } \\
\text { the angle of bed height, and } \\
\text { medication effects on afterload } \\
\text { Consider utilization of VA ECMO } \\
\text { as preferred intraoperative cardiac } \\
\text { support } \\
\text { Consider RVOTO as a cause of } \\
\text { hypotension }\end{array}$ \\
\hline Postoperative & $\begin{array}{l}\text { Awareness of } \\
\text { increased risk of } \\
\text { gastrointestinal and } \\
\text { endocrine } \\
\text { complications } \\
\text { Monitor } \\
\text { immunosuppression } \\
\text { levels closely } \\
\text { because of variable } \\
\text { biological uptake }\end{array}$ & $\begin{array}{l}\text { If single lung transplant is performed, } \\
\text { maintain awareness of differential } \\
\text { compliance and use ventilation } \\
\text { strategies to decrease risk of } \\
\text { hyperinflation of native lung }\end{array}$ & $\mathrm{N} / \mathrm{A}$ & $\begin{array}{l}\text { Consider postoperative prolongation } \\
\text { of VA ECMO in patients with } \mathrm{PH} \\
\text { as primary cause } \\
\text { Perform serial echocardiography to } \\
\text { assess biventricular remodeling as } \\
\text { VA ECMO is weaned }\end{array}$ \\
\hline
\end{tabular}

$G E R D$, gastro-esophageal reflux disease; $R V H$, right ventricular hypertrophy; $R V O T O$, right ventricular outflow obstruction; VA ECMO, veno-arterial extracorporeal membrane oxygenation

understanding the intricacies in the different management issues between $\mathrm{ECMO}$ and $\mathrm{CPB}$, identifying the implications of anesthetic management as it relates to ECMO and CPB, utilizing ECMO in both planned and unplanned circumstances, and recognizing patients that will benefit from prolonged ECMO $[7,13,14]$. Recent studies have shown that the use of intraoperative ECMO, compared to $\mathrm{CPB}$, for lung transplant reduces patient hospital length of stay (LOS), intensive care LOS, mechanical ventilation requirement, blood transfusion requirement, and 90-day mortality [13, 14], further emphasizing the need for the anesthesiologists' comprehensive understanding of ECMO management. As such, it is important to define the unique anesthetic challenges specific to the management of lung transplantation performed with venoarterial (VA) or venous-venous (VV) ECMO. VV ECMO is often used to bridge patients in respiratory failure to lung transplantation, offering full respiratory support. However, VV ECMO lacks the ability to support a patient hemodynamically for pulmonary hypertension and systemic hypotension, decompress the heart for surgical visualization, or control reperfusion after graft implantation [15]. VA ECMO in lung transplant functions to provide adequate gas exchange, hemodynamic support, and controlled reperfusion after graft transplantation $[15,16]$. Planned prolonged postoperative VA ECMO has been instituted for patients with pulmonary hypertension, right ventricular dysfunction, and early primary graft dysfunction [17]. A few key principles of intraoperative VA ECMO management for lung transplant include maintaining $20 \%$ of native cardiac output and bypassing $80 \%$ through ECMO circuit [16, 17], sustaining cardiac preload with end-tidal $\mathrm{CO}_{2}>$ $20 \mathrm{mmHg}$, and preserving pulsatility in both pulmonary and systemic arterial waveforms [16]. 


\section{The anesthesiologists' role in intraoperative echocardiography}

There is a dearth of evidence supporting the use of intraoperative transesophageal echocardiography (TEE) as there are no randomized patient-centered controlled trials demonstrating positive outcomes [18] in cardiothoracic surgery and its use in lung transplantation is only a class IIb indication [19]. Despite this, the benefits of real-time monitoring for hemodynamic compromise, fluid resuscitation, ventricular dysfunction, pulmonary vein, and artery anastomosis evaluation considerably outweigh any associated risks [20,21]. Furthermore, recent literature highlights cases where the use of TEE by anesthesiologists led to the intraoperative diagnosis, and subsequent intervention of pulmonary artery stenosis, right ventricular dysfunction, and pulmonary vein stenosis [20]. As such, incorporating advanced education in intraoperative echocardiography is essential for a lung transplant anesthesiology program [7]. In addition to obtaining a full perioperative examination, a curriculum must also focus on the ability to obtain and apply lung transplant-specific TEE data [7]. Critical points in education for TEE assessment include anesthetic induction for hemodynamic compromise, clamping of the pulmonary artery before pneumonectomy which can lead to right ventricular dysfunction and tricuspid regurgitation, and at graft reperfusion assessing for coronary air embolism [22]. After separating from ECMO or CPB to ensure adequate blood flow through the lungs, further TEE evaluation for stenosis should occur. Evaluation with color flow, continuouswave Doppler, and pulsed-wave Doppler of pulmonary veins (PV) (Table 4) and pulmonary arteries (PA) (Table 5) can aid in the diagnosis by determining turbulent flow and elevated velocities [20,23]. As many times the view of the left PA is masked by the left main stem bronchus, this may be difficult to visualize with TEE. Intraoperative TEE education should be considered a core element of lung transplant anesthesiology curriculum as effective and consistent use can contribute to rapid recognition of critical intraoperative events and instantaneous intervention.

\section{Patient blood management in lung transplantation}

There are currently no consensus guidelines on intraoperative transfusion and coagulation management for lung transplantation. Undoubtedly, there is an increased risk of blood loss in lung transplant patients due to the use of systemic anticoagulation, $\mathrm{CPB}$, or ECMO. As a result, blood product transfusion is nearly ubiquitous in the perioperative lung transplant period with recipients often receiving an average of three units of packed red blood cells (pRBCs) [24]. Perioperative transfusion is not without risk and the transplant anesthesiologist should be knowledgeable with the implications surrounding transfusion. In addition to typical transfusion-related adverse reactions, such as transfusionassociated circulatory overload (TACO), transfusion-related lung injury (TRALI), pneumonia, and sepsis, it is important to understand the consequences specifically in lung transplant recipients. Transfusion of greater than four units of pRBCs is associated with increased risk of PGD [12], while platelet transfusion has been associated with increased risk of chronic lung rejection, increased donor-specific human leukocyte antigen (HLA) antibodies [25], and all-cause mortality [24]. Where possible, efforts should be taken to judiciously transfuse transplant recipients.

\section{Postoperative management of lung transplantation}

\section{Exploring the role of anesthesiologists in postoperative management in lung transplantation}

The development of a successful lung transplant anesthesiology program must include an engaged and well-rounded postoperative service line. The predominance of anesthesiologists as primary post-surgical intensivists varies across the globe, yet the principles for developing a lung transplant anesthesiology program postoperative service line may be applied in the case of primary intensive care consultant or secondary consultant service role. As noted previously, the implementation of a comprehensive educational curriculum is crucial to developing a lung transplant anesthesiology program [7]. The potential impact of postoperative management on overall outcomes has been reported in the literature, and three areas of focus for postoperative service lines are the role of anesthesiologists in early recovery, analgesic interventions, and perioperative echocardiography $[4,6]$.

\section{The postoperative role of anesthesiologists in early recovery from lung transplantation}

Enhanced recovery protocols have been described as a way to coordinate complex care plans among multidisciplinary teams focused on improving outcomes in specific patient populations $[4,26]$. While no specific protocols exist for lung transplantation patients in the literature, an anesthesiology program should glean principles from both published thoracic enhanced recovery protocols, as well as various focused strategies for optimizing early recovery in lung transplantation [5, 9, 27-32].

In 2019, a group of international colleagues published the guidelines for enhanced recovery after lung surgery on behalf of the European Society of Thoracic Surgeons [9]. Recommendations for patients undergoing thoracic surgery included 45 items covering the entire perioperative period. One of the key recommendations in this paper related to postoperative recovery is that of early mobilization and 
physiotherapy (low evidence, strong recommendation). When these recommendations were assessed by thoracic anesthesiology colleagues, they noted the importance of perioperative lung protective ventilation, non-pharmacologic post-operative nausea and vomiting (PONV) prophylaxis, and pharmacologic PONV prophylaxis [28]. A recent single-center implementation of these protocols in thoracic surgery showed no significant difference in mortality, complications, length of stay, or patient-reported pain scores [29]. However, they did note that other studies which have shown improvements in outcomes had a higher implementation compliance rate $(>75 \%)$, as opposed to their reported rate of $60 \%$ [29]. Within lung transplantation, a postoperative early recovery program should perhaps focus on early mobilization, aggressive PONV prophylaxis, and high rates of compliance among the collaborative multidisciplinary team.

In addition to application of principles from thoracic surgical enhanced recovery guidelines, protocols for early recovery should focus on available data describing intraoperative variables that may affect postoperative early recovery. Colleagues from Foch Hospital noted that a low $\mathrm{PaO}_{2} / \mathrm{FiO}_{2}$ ratio $(<200)$, measured at the end of double lung transplantation, can predict an increased intensive care unit (ICU) length of stay and prolonged mechanical ventilation [30]. They also noted that inhaled nitric oxide (iNO) dependency at the end of transplantation was an early marker of increased risk of both PGD and longer term poor outcome [31]. Whereas patient mobility is a cornerstone of a thoracic early recovery protocol, Fessler et al. noted that the etiology of end-stage lung disease (ESLD) can affect postoperative recovery and extubation [5]. Retrospectively evaluating the course of all patients who underwent double lung transplantation at their institution from 2012 to 2019, they noted that patients presenting with either cystic fibrosis $(\mathrm{CF})$ or chronic obstructive pulmonary disease (COPD) were more frequently extubated in the operating room than other etiologies of ESLD $(p<0.001)$ [5]. The examination of their fast-track protocol and determining factors related to extubation in the operating room were recently followed up, with presenting ESLD, recipient body mass index, and $\mathrm{PaO}_{2} /$ $\mathrm{FiO}_{2}$ ratio 10 min after graft implantation noted to predict intraoperative extubation [32]. This study also reported that extubation in the operating room was predictive of decreased postoperative morbidity and mortality [32]. These important studies, which revolve around predictive factors of early postoperative morbidity, could be adapted by a lung transplant anesthesiology program to design an etiology-specific management strategy for early recovery in lung transplantation $[8,32]$.

\section{Postoperative role of anesthesiologists in establishing an analgesia service}

Due to the variability between patient presenting ESLD and diverse associated morbidities, postoperative pain management in the lung transplant population is challenging $[33,34]$. Poor analgesic control in these patients not only leads to perioperative morbidities, but can lead to long-term chronic pain resulting in decreased quality of life [35]. Therefore, it is imperative that a lung transplant anesthesiology program design a postoperative analgesic service that is based on the latest principles of multimodal analgesia to contribute optimal care to patients during recovery.

Historically, thoracic epidural analgesia (TEA) has been noted to be the gold standard within lung transplantation analgesia [36]. Colleagues from the University of Washington recently noted that preoperative placement of TEA resulted in decreased ICU LOS, hospital LOS, and opioid consumption [36]. Alternative analgesic approaches have included the use of paravertebral blocks, erector spinae blocks, and bilateral serratus anterior plane blocks [37-40]. While large datasets do not exist regarding the optimal regional analgesic approach to use within lung transplantation patients, a tailored approach based on the lung transplant program's expertise and patient co-morbidities is recommended to improve postoperative morbidities.

\section{Postoperative role of anesthesiologists in establishing an echocardiography service}

A postoperative echocardiography service should be designed to be available to evaluate the entire spectrum of lung transplantation that the patient needs, including evaluation of the implanted lung graft, biventricular function, pulmonary anastomoses, and ECMO cannulae [20, 41-46].

While intraoperative echocardiography is focused mainly on TEE, postoperative echocardiography may be either TEE or transthoracic echocardiography (TTE). The emergence of point of care ultrasound has led to the use of perioperative ultrasound to evaluate implanted lung graft function, to include evaluation of pulmonary edema, pneumothorax, pleural effusion, or pleural consolidation [41]. The use of frequent echocardiographic evaluation of biventricular function is particularly important in patients presenting with primary pulmonary hypertension as the presenting etiology of ESLD, as they are at risk of hemodynamic instability secondary to right ventricular outflow obstruction and postoperative biventricular remodeling $[42,43]$.

Postoperative echocardiographic monitoring of the patency of pulmonary vasculature anastomoses, both arterial and venous, is key for rapid diagnosis of acute graft dysfunction [20, 44]. Another etiology of acute graft dysfunction may lie in the misalignment or malfunction of postoperative ECMO cannulae. The postoperative echocardiography service should be aware of the significant diversity of both $\mathrm{VV}$ and VA ECMO cannulae configurations, as rapid assessment of hypoxemia or hemodynamic instability may arise from a variety of ECMO-related complications including recirculation, malposition, or thrombosis-related sequelae $[45,46]$. 


\section{Conclusion}

The evolving role of anesthesiologists as leaders in the perioperative multidisciplinary lung transplantation team exposes the developing need for lung transplant anesthesiology education programs. As the need for lung transplant grows, so does the need for education programs focused on building multidisciplinary teams of dedicated medical specialists [47]. The importance of developing an education program has been highlighted in the literature, showing that the optimized intraoperative management by anesthesiologists improves patient outcomes $[4,5,7]$. The development of a clinical and educational program that focuses on lung transplant anesthesia, from the preoperative multidisciplinary care pathway, through comprehensive intraoperative management, to the multifaceted postoperative care, will further validate the role of anesthesiologists as leaders in the lung transplant team.

Acknowledgements The authors would like to thank Barbara Weisser, Mayo Clinic Academic Support Office, Scottsdale, AZ.

Funding Nil.

\section{Declarations}

Ethical approval Not applicable.

Informed consent Not applicable.

Conflict of interest The authors declare no competing interests.

\section{References}

1. Hardy JD. The first lung transplant in man (1963) and the first heart transplant in man (1964). Transplant Proc. 1999;31:25-9. https:// doi.org/10.1016/S0041-1345(98)02059-4.

2. Sellers D, Cassar-Demajo W, Keshavjee S, Slinger P. The evolution of anesthesia for lung transplantation. J Cardiothorac Vasc Anesth. 2017;31:1071-9. https://doi.org/10.1053/j.jvca.2016.11. 034.

3. Chambers DC, Zuckermann A, Cherikh WS, et al. The International Thoracic Organ Transplant Registry of the International Society for Heart and Lung Transplantation: 37th adult lung transplantation report - 2020; focus on deceased donor characteristics. J Heart Lung Transplant. 2020;39:1016-27. https:// doi.org/10.1016/j.healun.2020.07.009.

4. Martin AK, Yalamuri SM, Wilkey BJ, et al. The impact of anesthetic management on perioperative outcomes in lung transplantation. J Cardiothorac Vasc Anesth. 2020;34:1669-80. https://doi. org/10.1053/j.jvca.2019.08.037.

5. Fessler J, Davignon M, Sage E, et al. Intraoperative implications of the recipients' disease for double-lung transplantation. J Cardiothorac Vasc Anesth. 2021;35:530-8. https://doi.org/10. 1053/j.jvca.2020.07.039.
6. Martin AK, Renew JR, Jayaraman AL, Murray AW, Fritz AV, Ramakrishna H. Analysis of outcomes in lung transplantation. J Cardiothorac Vasc Anesth. 2019;33:1455-66. https://doi.org/10. 1053/j.jvca.2018.06.014.

7. Wilkey BJ, Abrams BA, Del Rio JM, et al. Statement from the Society for the Advancement of Transplant Anesthesia: white paper advocating desirable milestones and competencies for anesthesiology fellowship training in the field of lung transplantation. Semin Cardiothorac Vasc Anesth. 2020;24:104-14. https://doi.org/10. 1177/1089253219867695.

8. Martin AK, Fritz AV, Wilkey BJ. Anesthetic management of lung transplantation: impact of presenting disease. Curr Opin Anaesthesiol. 2020;33:43-9. https://doi.org/10.1097/Aco. 0000000000000805 .

9. Batchelor TJP, Rasburn NJ, Abdelnour-Berchtold E, et al. Guidelines for enhanced recovery after lung surgery: recommendations of the Enhanced Recovery After Surgery (ERAS(R)) Society and the European Society of Thoracic Surgeons (ESTS). Eur J Cardiothorac Surg. 2019;55:91-115. https://doi.org/10.1093/ejcts/ ezy301.

10. Minai OA, Yared J-P, Kaw R, Subramaniam K, Hill NS. Perioperative risk and management in patients with pulmonary hypertension. Chest. 2013;144:329-40. https://doi.org/10.1378/ chest.12-1752.

11. Lenihan M, Mullane D, Buggy D, Flood G, Griffin M. Anesthesia for lung transplantation in cystic fibrosis: retrospective review from the Irish National Transplantation Centre. J Cardiothorac Vasc Anesth. 2018;32:2372-80. https://doi.org/10.1053/j.jvca.2017.11. 041.

12. Diamond JM, Lee JC, Kawut SM, et al. Clinical risk factors for primary graft dysfunction after lung transplantation. J Heart Lung Transplant. 2013;32:S43-S. https://doi.org/10.1016/j.healun.2013. 01.911.

13. Fessler J, Sage E, Roux A, et al. Is extracorporeal membrane oxygenation withdrawal a safe option after double-lung transplantation? Ann Thorac Surg. 2020;110:1167-74. https://doi.org/10. 1016/j.athoracsur.2020.03.077.

14. Machuca TN, Collaud S, Mercier O, et al. Outcomes of intraoperative extracorporeal membrane oxygenation versus cardiopulmonary bypass for lung transplantation. J Thorac Cardiovasc Surg. 2015;149:1152-7. https://doi.org/10.1016/j.jtcvs.2014.11.039.

15. Hashimoto K, Hoetzenecker K, Yeung JC, et al. Intraoperative extracorporeal support during lung transplantation in patients bridged with venovenous extracorporeal membrane oxygenation. J Heart Lung Transplant. 2018;37:1418-24. https://doi.org/10. 1016/j.healun.2018.07.003.

16. Thomas M, Martin AK, Allen WL, et al. Lung transplantation using a hybrid extracorporeal membrane oxygenation circuit. ASAIO J. 2020;66:e123-e25. https://doi.org/10.1097/Mat.0000000000001157.

17. Hoetzenecker K, Schwarz S, Muckenhuber M, et al. Intraoperative extracorporeal membrane oxygenation and the possibility of postoperative prolongation improve survival in bilateral lung transplantation. J Thorac Cardiovasc Surg. 2018;155:2193-206 e3. https:// doi.org/10.1016/j.jtcvs.2017.10.144.

18. Michelena HI, Suri RM, Malouf J, Enriquez-Sarano M, Mankad SV. Adult perioperative echocardiography: anatomy, mechanisms and effective communication. Prog Cardiovasc Dis. 2014;57:74 90. https://doi.org/10.1016/j.pcad.2014.05.004.

19. Kim KK, Krause M, Brandes IF, Khanna AK, Bartels K. Transesophageal echocardiography for perioperative management in thoracic surgery. Curr Opin Anaesthesiol. 2021;34:7-12. https:// doi.org/10.1097/ACO.0000000000000947. 
20. Abrams BA, Melnyk V, Allen WL, et al. TEE for lung transplantation: a case series and discussion of vascular complications. J Cardiothorac Vasc Anesth. 2020;34:733-40. https://doi.org/10. 1053/j.jvca.2019.09.005.

21. Iyer MH, Bhatt A, Kumar N, Hussain N, Essandoh MK. Transesophageal echocardiography for lung transplantation: a new standard of care? J Cardiothorac Vasc Anesth. 2020;34:7413. https://doi.org/10.1053/j.jvca.2019.10.025.

22. Serra E, Feltracco P, Barbieri S, Forti A, Ori C. Transesophageal echocardiography during lung transplantation. Transplant Proc. 2007;39:1981-2. https://doi.org/10.1016/j.transproceed.2007.05. 004.

23. Essandoh M, Bhatt A, Flores A, Whitson B. Transesophageal echocardiography monitoring during lung transplantation. J Cardiothorac Vasc Anesth. 2017;31:e98-9. https://doi.org/10.1053/j.jvca.2017.03.041.

24. Pena JJ, Bottiger BA, Miltiades AN. Perioperative management of bleeding and transfusion for lung transplantation. Semin Cardiothorac Vasc Anesth. 2020;24:74-83. https://doi.org/10. $1177 / 1089253219869030$.

25. Snyder LD, Wang Z, Chen D-F, et al. Implications for human leukocyte antigen antibodies after lung transplantation: a 10-year experience in 441 patients. Chest. 2013;144:226-33. https://doi. org/10.1378/chest.12-0587.

26. Oprea AD, Perrino AC Jr, Popescu WM. Enhanced recovery after lung surgery: fad or fashion? J Cardiothorac Vasc Anesth. 2019;33: 2445-7. https://doi.org/10.1053/j.jvca.2019.03.061.

27. Hernandez-Torres V, Ratzlaff R, Thomas M, Narula T, Martin AK. The use of a novel endotracheal tube and airway management system to prevent complications in lung transplantation. Cureus. 2019;11:e5170. https://doi.org/10.7759/cureus.5170.

28. Teeter EG, Kolarczyk LM, Popescu WM. Examination of the enhanced recovery guidelines in thoracic surgery. Curr Opin Anaesthesiol. 2019;32:10-6. https://doi.org/10.1097/ACO. 0000000000000681

29. Khoury AL, Kolarczyk LM, Strassle PD, et al. Thoracic enhanced recovery after surgery: single academic center observations after implementation. Ann Thorac Surg. 2021;111:1036-43. https://doi. org/10.1016/j.athoracsur.2020.06.021.

30. Fessler J, Thes J, Pirracchio R, et al. Prognostic value of the $\mathrm{PaO} 2$ /FiO2 ratio determined at the end-surgery stage of a double-lung transplantation. Clin Transplant. 2019;33:e13484. https://doi.org/ 10.1111/ctr.13484.

31. Fessler J, Godement M, Pirracchio R, et al. Inhaled nitric oxide dependency at the end of double-lung transplantation: a boosted propensity score cohort analysis. Transpl Int. 2019;32:244-56. https://doi.org/10.1111/tri.13381.

32. Fessler J, Fischler M, Sage E, et al. Operating room extubation: a predictive factor for 1-year survival after double-lung transplantation. J Heart Lung Transplant. 2021;40:334-42. https://doi.org/10. 1016/j.healun.2021.01.1965.

33. Gelzinis TA. An update on postoperative analgesia following lung transplantation. J Cardiothorac Vasc Anesth. 2018;32:2662-4. https://doi.org/10.1053/j.jvca.2018.05.014.

34. Gimenez-Mila M, Videla S, Pallares N, et al. Impact of surgical technique and analgesia on clinical outcomes after lung transplantation: a STROBE-compliant cohort study. Medicine (Baltimore). 2020;99:e22427. https://doi.org/10.1097/MD.0000000000022427.

35. Loxe SC, de Mello LS, Camara L, et al. Chronic pain after lung transplantation and its impact on quality of life: a 4-year follow-up.
Transplant Proc. 2020;52:1388-93. https://doi.org/10.1016/j. transproceed.2020.02.032.

36. McLean SR, von Homeyer P, Cheng A, et al. Assessing the benefits of preoperative thoracic epidural placement for lung transplantation. J Cardiothorac Vasc Anesth. 2018;32:2654-61. https://doi. org/10.1053/j.jvca.2018.04.002.

37. Hutchins J, Apostolidou I, Shumway S, et al. Paravertebral catheter use for postoperative pain control in patients after lung transplant surgery: a prospective observational study. J Cardiothorac Vasc Anesth. 2017;31:142-6. https://doi.org/10.1053/j.jvca.2016.05. 006 .

38. Huang W, Wang W, Xie W, Chen Z, Liu Y. Erector spinae plane block for postoperative analgesia in breast and thoracic surgery: a systematic review and meta-analysis. J Clin Anesth. 2020;66: 109900. https://doi.org/10.1016/j.jclinane.2020.109900.

39. Anderson AJ, Marciniak D. Bilateral serratus anterior plane (SAP) catheters: a novel approach to promote postoperative recovery after bilateral sequential lung transplantation. J Cardiothorac Vasc Anesth. 2019;33:1353-5. https://doi.org/10.1053/j.jvca.2018.07. 051.

40. Kelava M, Anthony D, Elsharkawy H. Continuous erector spinae block for postoperative analgesia after thoracotomy in a lung transplant recipient. J Cardiothorac Vasc Anesth. 2018;32:e9-11. https://doi.org/10.1053/j.jvca.2018.04.041.

41. Prada G, Vieillard-Baron A, Martin AK, et al. Tracheal, lung, and diaphragmatic applications of M-mode ultrasonography in anesthesiology and critical care. J Cardiothorac Vasc Anesth. 2021;35: 310-22. https://doi.org/10.1053/j.jvca.2019.11.051.

42. Moser B, Jaksch P, Taghavi S, et al. Lung transplantation for idiopathic pulmonary arterial hypertension on intraoperative and postoperatively prolonged extracorporeal membrane oxygenation provides optimally controlled reperfusion and excellent outcome. Eur J Cardiothorac Surg. 2018;53:178-85. https://doi.org/10.1093/ejcts/ ezx212.

43. Prada G, Vieillard-Baron A, Martin AK, et al. Echocardiographic applications of M-mode ultrasonography in anesthesiology and critical care. J Cardiothorac Vasc Anesth. 2019;33:1559-83. https:// doi.org/10.1053/j.jvca.2018.06.019.

44. Kumar N, Essandoh M, Bhatt A, et al. Pulmonary cuff dysfunction after lung transplant surgery: a systematic review of the evidence and analysis of its clinical implications. J Heart Lung Transplant. 2019;38:530-44. https://doi.org/10.1016/j.healun.2019.01.005.

45. Martin AK, Jayaraman AL, Nabzdyk CG, et al. Extracorporeal membrane oxygenation in lung transplantation: analysis of techniques and outcomes. J Cardiothorac Vasc Anesth. 2021;35:64461. https://doi.org/10.1053/j.jvca.2020.05.014.

46. Martin AK, Allen WL, Fritz AV, Diaz-Gomez JL. Successful rescue utilization of intraoperative tissue plasminogen activator in the setting of massive thrombosis of Avalon catheter and patient in extremis with refractory hypoxemia. J Cardiothorac Vasc Anesth. 2018;32:2278-81. https://doi.org/10.1053/j.jvca.2017.12.009.

47. Nguyen AT, Brzezinski M, Chen J, Nguyen NV, Dinh LV, Kukreja J. Lung transplant programs in developing countries: challenges, solutions, and outcomes. Curr Opin Organ Transplant. 2020;25: 299-304. https://doi.org/10.1097/MOT.0000000000000766.

Publisher's note Springer Nature remains neutral with regard to jurisdictional claims in published maps and institutional affiliations. 